\title{
A study of short term heart rate variability in dipping tobacco users
}

\author{
M.I. Glad Mohesh', K. Ratchagan', A. Sundaramurthy ${ }^{2}$ \\ ${ }^{1}$ Department of Physiology, Shri Sathya Sai Medical College \& RI, Ammapettai, Sembakkam Post, Kancheepuram District, Tamilnadu State, \\ South India, ${ }^{2}$ Department of Pulmonary Medicine, Shri Sathya Sai Medical College \& RI, Ammapettai, Sembakkam Post, Kancheepuram \\ District, Tamilnadu State, South India
}

\section{A B S T R A C T}

Background: WHO (2010) reported the rise in the number of smokeless tobacco users in India. Dipping tobacco is a form of smokeless tobacco being used in these region in various trade names. Nicotine in smoking tobacco is found to alter the cardiovascular autonomic functions. As the expected cardiovascular mortality due to tobacco use across the globe is very high, here we studied the effect of dipping tobacco on cardiovascular autonomic function using the short term heart rate variability (HRV) analysis. Methods: Five minutes Lead II ECG at rest is aquired from male dipping tobacco moderate users $(n=30)$ and age matched controls $(n=30)$. Frequency and time domain parameters were derived and analysed using the Kubios HRV analysis software. Blood pressure changes were also compared. Unpaired ' $\mathrm{t}$ ' test was done using SPSS 17.0 and statistical significance was set at $p<0.05$. Results: Significant changes in certain parameters indicated that there is a developing set back in the sympathetic control over the heart (LF, 383.8 +115.8, 952.8+131.1, p<0.01) and also an established increase in diastolic blood pressure $(73.1+2.8,65.48+1.5, p<0.01)$. Conclusion: Dipping tobacco a form of smokeless tobacco is equally harmful like any smoked tobacco in altering the cardiovascular autonomic function. Thereby the increase in smokeless tobacco users in India or any country is going to add up more to the mortality rate due to tobacco related diseases in near future as estimated by WHO. An immediate measure to stop the production, sale and use of these smokeless tobacco products could curb this menace.

Key words: Smokeless tobacco, heart rate variability, dipping tobacco, cardiovascular, autonomic functions

\section{INTRODUCTION}

World Health Organisation (WHO) reports on global status of non-communicable diseases (2010) say that smoking is to cause an estimated $71 \%$ of all lung cancer deaths, $42 \%$ of chronic respiratory diseases and nearly $10 \%$ of cardiovascular diseases. Smoking is also an important risk factor for communicable diseases such as tuberculosis and lower respiratory infections. Smokeless tobacco has been associated with oral cancer, hypertension, heart disease and other conditions. Expected deaths due to tobacco use in the year 2020 is around 8 millions. ${ }^{1}$ Smokeless tobacco includes tobacco products like Khaini, Gutkha, Pan masala, Moist snuff (dipping tobacco) etc. Prevalence of smokeless tobacco use $26 \%$ is far more greater than the use of
Access this article online

Website:

http://nepjol.info/index.php/AJMS 
physiological effects of nicotine in any form is influenced by a lot of confounding factors like tolerance, desensitization of receptors, level of addiction, smoking, diet, physical activity, etc. Our hypothesis that the use of dipping tobacco decreases the heart rate variability, which in turn may increase the rate of morbidity \& mortality due to cardiovascular diseases induced by tobacco in the years to come. Hence here in this study, our objective is to understand the short term heart rate variability status of the dipping tobacco users in comparison to that of the other normal subjects who never use tobacco in any form.

\section{MATERIALS AND METHODS}

The present study was conducted at Research lab, Department of Physiology, Shri Sathya Sai Medical College \& RI, Ammapettai, Kancheepuram District. A total of 60 healthy male volunteers between the ages of 18-28 years were inducted into the study. They were grouped into study subjects (Group $I=30$ ) who were using dipping tobacco only and who scored 4-6 in the Fagerstroms nicotine dependence-smokeless tobacco questionnaire (FNDT). ${ }^{5}$ Subjects who exercise regularly and use other forms of tobacco, alcoholics, and who suffered diseases like Diabetes mellitus, Hypertension and other cardio-respiratory problems were excluded. Sedentary age matched male subjects served as controls (Groups II-30). Institutional Ethics committee approval was obtained before the start of the study. Subjects under medication for any kind of illness were also excluded from the study.

Recruited subjects were asked to report to the Research Lab, Department of physiology at a fixed time, $8 \mathrm{am}$ to $10 \mathrm{am}$. Overnight abstinence from tobacco use was recommended. Subjects were also asked to skip any beverages like tea, coffee, or carbonated drinks. Exercise of any kind were asked to be postponed. Breakfast was allowed only 2 hours before reporting for the study. Once arrived, subject's anthropometric details were taken which included Name, Age, Sex, Occupation, Height and weight. Blood pressure was recorded using a digital sphygmomanometer (OMRON HEM 4021). BMI was derived by Quetelets index.

After resting in supine position for 10 minutes, Lead II ECG was recorded by a HRV module using Audacity software version 1.3 for a period of 5 minutes when the subjects were fully relaxed and breathing normally. Sampling rate was set at 8000 samples/sec higher than the recommended minimum of 1024 samples $/ \mathrm{sec}^{6}{ }^{6}$ Short term HRV analysis of 5 minutes was done using Kubios HRV version 2.0, HRV analysis software.

HRV was analysed for both time and frequency domain measures in accordance with the task force of European society of Cardiology and the North American Society of pacing electrophysiology. ${ }^{6}$

Time domain measures includes the mean RR interval, mean heart rate, Square root of the mean squared differences between successive RR intervals (RMSSD), Number of successive RR interval pairs that differ more than $50 \mathrm{~ms}$ (NN50), NN50 divided by the total number of RR intervals (pNN50).

Frequency domain measures include the Very Low frequency (VLF), Low frequency (LF), and High frequency (HF). The collected data was stored in Microsoft-Excel for windows 2007 and analysed for statistical significance using Statistical Package for the Social Sciences ver.17.0. With normal distribution of the collected data we followed parametric unpaired " $\mathrm{t}$ " test and significance was set at $\mathrm{p}<0.05$.

\section{RESULTS}

Table 1 explains the anthropometric characteristics of subjects like age, weight, body mass index, systolic and diastolic blood pressure. There was no statistically significant difference between the control and study group subjects in terms of age, bodyweight and systolic Blood pressure. But the results showed statistically significant difference in body mass index and diastolic blood pressure $(\mathrm{p}<0.05)$.

Table 2 explains the comparison of time domain measures of heart rate variability among the two groups during normal breathing. Changes in the parameter NN50 is statistically significant, whereas all other parameters like RMSSD, mean RR, mean HR did not show any statistically significant difference.

Table 3 explains the comparison of frequency domain measures of heart rate variability among the two groups. Except for the two parameters VLF and Low frequency

\begin{tabular}{|c|c|c|c|}
\hline Parameter & $\begin{array}{c}\text { Control } \\
\text { group } \\
\text { (mean } \pm \text { SEM) }\end{array}$ & $\begin{array}{c}\text { dipping } \\
\text { tobacco users } \\
\text { (mean } \pm \text { SEM) }\end{array}$ & $P$ value \\
\hline Age (years) & $22.24 \pm 0.63$ & $23.78 \pm 0.81$ & 0.17 \\
\hline Weight (kgs) & $66.35 \pm 2.9$ & $59.0 \pm 4.38$ & 0.19 \\
\hline BMI $\left(\mathrm{kg} / \mathrm{m}^{2}\right)$ & $23.74 \pm 0.86$ & $17.97 \pm 1.10$ & $0.001^{*}$ \\
\hline Syst BP (mmHg) & $119.4 \pm 2.1$ & $125.4 \pm 4.44$ & 0.17 \\
\hline Diast BP $(\mathrm{mmHg})$ & $65.48 \pm 1.56$ & $73.11 \pm 2.87$ & $0.01^{*}$ \\
\hline
\end{tabular}




\begin{tabular}{|c|c|c|c|}
\hline Parameters & $\begin{array}{c}\text { Control } \\
\text { group } \\
\text { (mean } \pm \text { SEM) }\end{array}$ & $\begin{array}{c}\text { dipping } \\
\text { tobacco users } \\
\text { (mean } \pm S E M)\end{array}$ & $P$ value \\
\hline Mean RR (ms) & $813.4 \pm 16.48$ & $812.1 \pm 31.92$ & 0.97 \\
\hline Mean HR (beats/min) & $74.83 \pm 1.54$ & $74.85 \pm 2.78$ & 0.99 \\
\hline RMSSD (ms) & $59.63 \pm 10.72$ & $34.75 \pm 6.60$ & 0.17 \\
\hline NN50 (count) & $118.6 \pm 18.0$ & $27.88 \pm 11.45$ & $0.005^{*}$ \\
\hline pNN50\% & $29.10 \pm 4.78$ & $6.74 \pm 2.93$ & $0.009^{*}$ \\
\hline
\end{tabular}

\begin{tabular}{|c|c|c|c|}
\hline Parameters & $\begin{array}{c}\text { Control } \\
\text { group } \\
\text { (mean } \pm S E M)\end{array}$ & $\begin{array}{c}\text { dipping } \\
\text { tobacco users } \\
\text { (mean } \pm \text { SEM) }\end{array}$ & $P$ value \\
\hline VLF power $\left(\mathrm{ms}^{2}\right)$ & $982.8 \pm 171.6$ & $320.0 \pm 74.16$ & $0.02^{*}$ \\
\hline LF power $\left(\mathrm{ms}^{2}\right)$ & $952.8 \pm 131.1$ & $383.8 \pm 115.8$ & $0.017^{*}$ \\
\hline HF power $\left(\mathrm{ms}^{2}\right)$ & $1305 \pm 304.5$ & $466.3 \pm 213.5$ & 0.11 \\
\hline LF power (nu) & $51.67 \pm 3.77$ & $50.85 \pm 4.54$ & 0.90 \\
\hline HF power (nu) & $47.95 \pm 3.71$ & $48.75 \pm 4.51$ & 0.90 \\
\hline Total power $\left(\mathrm{ms}^{2}\right)$ & $2680 \pm 398.5$ & $1173 \pm 381.9$ & 0.06 \\
\hline LF: HF ratio & $1.33 \pm 0.17$ & $1.16 \pm 0.19$ & 0.5 \\
\hline
\end{tabular}

(LF) all others showed no statistically significant difference. These two are of indicators of high sympathetic activity which is of concern to be discussed as really potent changes seen among the groups.

\section{DISCUSSION}

Smokeless tobacco affects the cardiovascular system and causes diseases like, myocardial infarction, stroke, and high blood pressure. ${ }^{7-10}$ Impact of the nicotine on cardiovascular autonomic functions can be best diagnosed using the Heart rate variability assessment. Short term HRV analysis from a 5 minute record of lead II ECG is a better way for understanding the autonomic status. Smoking tobacco has been proved to alter the ANS by many studies published. ${ }^{11,12}$ Effect of smokeless tobacco on the cardiovascular autonomic functions was studied through this HRV assessment. The subjects of our study were using smokeless tobacco (dipping tobacco product) moderately as they scored between (4-6) in the Fagerstroms nicotine dependence score.

The smokeless tobacco users in this study are very young at age and were in the productive part of their life. There was a significant decrease in BMI, maybe an impact of the nicotine, that suppresses the feel of hunger leading to decreased food intake thereby lowering the body weight. These men belonging to the working age group needs a lot of energy and if they develop irregularities in intake of food, this may lead to diseases like gastric ulcer which will affect their productivity at work.

Nicotine causes vasoconstriction possibly through alteration of a cyclic-GMP-dependant vasoactive mechanism. ${ }^{13}$ Significant rise in the diastolic blood pressure is of great concern to note as any increase in the diastolic BP is an indicator of hypertension. This will lead to all possible cardiovascular diseases in near future. In a study done earlier $35 \%$ of their subjects remained as hypertensives in a masked status until diagnosed by an ambulatory blood pressure measurement. ${ }^{14} \mathrm{HRV}$ studies would rule out these cases very easily serving as a diagnostic tool.

A significant decrease in the NN50 values of the time domain measure indicates a very high autonomic failure. There is an existing strong correlation between the percentage of patients with abnormal counts and the extent of autonomic neuropathy determined from conventional measures. ${ }^{15,16}$ Dipping tobacco might be the causative agent for this failure in these subjects.

Frequency domain measures also showed significant decrease in the Very low frequency (VLF) and LF, power among the two groups. They represent basically the sympathetic activity of the heart. VLF can be analysed only for HRV recordings greater than 20 minutes and hence at this point we donot report any importance here. Reduction in the power of all spectral bands is the most common finding in diabetic autonomic neuropathy. ${ }^{17,18}$ Significantly decreased LF power shows an impaired sympathetic activity.

Dipping tobacco users were moderately nicotine dependent in this study, still we were able to record that they were weak in their sympathetic control over their heart. Both time domain and frequency domain measures of HRV were able to show that there is decrement in the autonomic control of the heart although the intensity is less. Intervention in the form of quitting dipping tobacco use might help them to regain their losing autonomic control over heart.

\section{CONCLUSION}

Heart rate variability analysis of moderate users of dipping tobacco in this study has revealed the disturbances in the sympathovagal balance in the regulation of cardiac activity. We also conclude that smoked or smokeless type, tobacco damages/decreases the cardiovascular autonomic 
functions. Thereby it is established that smokeless tobacco is also harmful similar to that of smoking tobacco.

\section{ACKNOWLEDGEMENT}

We thank the Management and the Dean of Shri Sathya Sai Medical College \& RI, Ammapettai, Kancheepuram District to have permitted and supported this project. We are also grateful to Dr. Maruthy Annapurna, Professor of Physiology, Narayana Medical College, Nellore for his Lead II ECG device with high sampling rate and the technical assistance he has provided us for the acquisition and analysis of HRV.

We also thank Dr.Elizabeth Tharion, Professor of Physiology, CMC Vellore for her valuable suggestions in the recording and analysis of the HRV reports

\section{REFERENCES}

1. Global status report on non-communicable diseases. WHO Library Cataloguing - in- Publication. 2010; Data, ISBN 9789240686458. p-01.

2. Global Adult Tobacco Survey India report (2009-10). Ministry of Health and Family Welfare, Government of India, New Delhi. 2010; p-72.

3. Reddy KS and Gupta PC. Reports on Tobacco control in India. Ministry of Health and Family Welfare, Government of India, New Delhi.2010; p- 45.

4. Nicholas S and Saint DA. A Single $4 \mathrm{mg}$ Dose of Nicotine decreases Heart Rate Variability in Healthy Non-smokers: Implications for Smoking Cessation Programs. Nicotine Tob Res 2011; ntr004 doi: 10.1093/ntr/ntr004.

5. Ebbert JO, Patten CA and Schroeder DR. The Fagerstrom Test for Nicotine Dependence-Smokeless Tobacco (FTND-ST). Addictive Behaviours 2006; 31(9):1716-1721.

6. Standards of measurement, physiological interpretation, and clinical use. European Heart Journal 1996; 17: 354-381.

7. Wolk R, Shamsuzzaman A, Svatikova A, Huyber C, Huck C, Narkiewicz K, et al. Hemodynamic and autonomic effects of smokeless tobacco in healthy young men. Journal of the American College of Cardiology, 2005; 45(6): 910-914.

8. Huhtasaari F, Lundberg V, Eliasson M, Janlert $U$, and Asplund K. Smokeless tobacco as a possible risk factor for myocardial infarction: A population-based study in middle- aged men. Journal of the American College of Cardiology, 1999; 34: 17841790.

9. Gupta R, Gurm H, and Bartholomew J. Smokeless tobacco and cardiovascular risk. Archives of Internal Medicine, 2004;164:1845-1849.

10. Bolinder G, Alfredsson L, Englund A, and de Faire. Smokeless tobacco use and increased cardiovascular mortality among Swedish construction workers. American Journal of Public Health 1994; 84: 399-404.

11. Tayade MC and Kulkarni NB. The Effect of smoking on the cardiovascular autonomic functions: A cross sectional study. Journal of clinical diagnostic and research 2013;7(7):1307-1310.

12. Niedermaier ON, Smith ML, Beightol LA, Zukowska-Grojec Z, Goldstein DS and Eckberg DL. Influence of cigarette smoking on human autonomic function. Circulation1993;88:562-571.

13. Halimi JM and Mimran A. Renal effects of smoking: potential mechanisms and perspectives. Nephrol Dial Transplant 2000; 15:938-940.

14. Pannarale G, Acconcia MC, Gianturco L, Mirabelli F, Licitra $\mathrm{R}$, Mutonoe D, et al. Cigarette smoking and ambulatory blood pressure: a case-control study in normotensives. Journal of Human Hypertension 2008; 22:129-131.

15. Ewing DJ, Neilson JMM, Shapiro JA and Reid W. Twenty four $\mathrm{n}$ hour heart rate variability: effects of posture, sleep and time of day in healthy controls and comparison with bedside tests of autonomic function in diabetic patients. Br Heart J 1991; 65: 239-244.

16. Malpas SC and Maling TJB. Heart rate variability and cardiac autonomic function in diabetes. Diabetes 1990; 39: 11771181.

17. Bianchi A, Bontempi B, Cerutti S, Gianogli P, Comi G and Natali Sora MG. Spectral analysis of heart rate variability signal and respiration in diabetic subjects. Med Biol Eng Comput 1990 ; 28: 205-211.

18. Bellavere F, Balzani I, De Masi G, Carraro M, Carenza P, Cobelli $\mathrm{C}$, et al. Power spectral analysis of heart rate variation improves assessment of diabetic cardiac autonomic Neuropathy. Diabetes 1992; 41: 633- 640.

Authors Contribution:

GM - designed the study, performed the laboratory tests, analysed the data, drafted the manuscript, \& reviewed the manuscript; KR - Contributed to the study design; AS - Reviewed the manuscript.

Source of Support: Nil, Conflict of Interest: None declared. 